\title{
Circulations in the Global History of Art
}

Petersen, Anne Ring

Published in:

Journal of World History

Publication date:

2017

Document version

Publisher's PDF, also known as Version of record

Document license:

Unspecified

Citation for published version (APA):

Petersen, A. R. (2017). Circulations in the Global History of Art. Journal of World History, 28(1), $172-174$.

https://muse-jhu-edu.ep.fjernadgang.kb.dk/article/663561 


\section{Journal of}
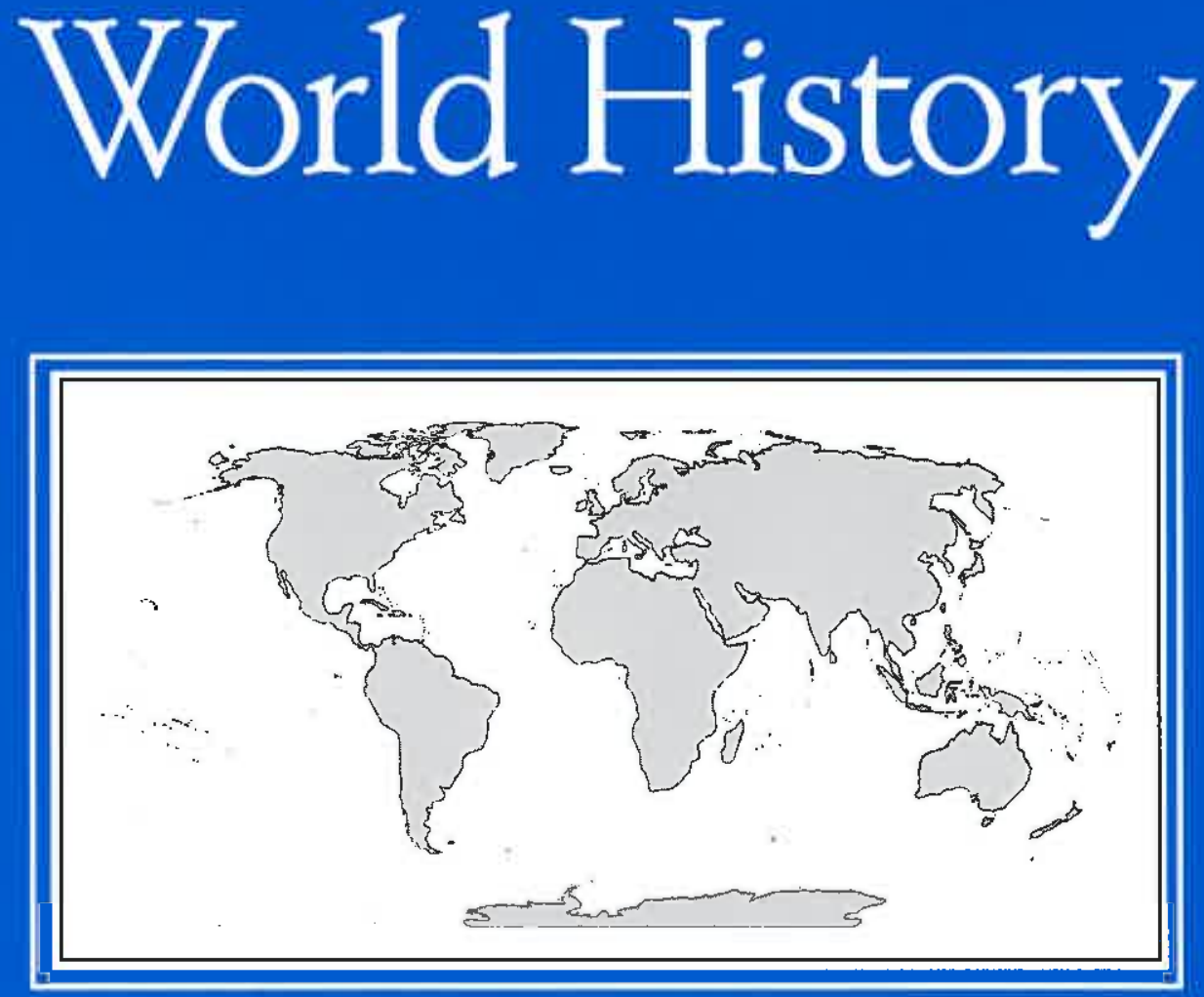

OFFICLAL IOURNAL OF THE WORLD HISTORY ASSOGIATION

Volume 28 - Number I - March 2017 
Circulations in the Global History of Art. Edited by THOMAS DACOSTA KAUFMANN, CATHERINE DOSSIN, and BEATRICE IOYEUX-PRUNEL. New York: Routledge, 2016. 247 pp. \$rog.95 (cloth), \$90.02 (ebook).

Historical interest in cultural circulation and exchange has increased in the zooos. In recent years, this interest in the "globalization" of cultures has also spread to the specialized field of art history, which has seen a proliferation of writings on "world art history," "global art history," and the worldwide spread of the discipline of art history itself. In this emerging field of comparative historical studies in the visual arts, the volume Circulations in the Global History of Art stands out with its determined rejection of the nation as the privileged unit of analysis and its cogent emphasis on processes and connections among cultures.

As the title suggests, the book's leading concept is "circulation." The introduction by editors Thomas DaCosta Kaufmann, Catherine Dossin, and Béatrice Joyeux-Prunel, all leading scholars of global art history, provides a substantial account of the historical background of the recent explorations of circulation in global art history. The book brings together the work of historians and art historians from the United States, France, Germany, and Poland, thus presenting a broad range of Western approaches. It includes specialized case studies of different periods, regions, and objects, and covers a variety of methodological and historiographical issues related to circulation and globalization. In his illuminating discussion of the historiography pertaining to global and world art history, Kaufmann traces how much of the early methodology for the study of intercultural artistic circulation was rooted in the discipline of history, specifically German Historicism of the nineteenth century and the work of the French Annales School in the twentieth century. The book also links the two disciplines by including chapters by three historians who have contributed significantly to the development of new approaches to history in the context of a postcolonial, globalized world, such as Entangled or Global History and Transnational History: Michel Espagne, Serge Gruzinski, and Christophe Charle.

The subsequent chapters demonstrate how circulatory approaches may help us revise the usual frames and tropes of (art) historical narratives. Even if the authors take most of their empirical examples from the histories of the fine and applied arts, their revisionist approaches may also inspire historians working with (visual) historical documents and intercultural comparative perspectives in other fields, because the contributors all insist on the inseparable bond between theory and 
methodological self-reflection, on the one hand, and the practice of historical analysis, on the other.

The strong emphasis on history in this book is a much-needed antidote to the pervasive presentism in global art studies, which holds that we live in the first truly global age-a presentism that is partly explained by the fact that much current debate relates to contemporary art. Kaufmann rightly insists on globalizing moments before circa I 800 and on the fact that art has always depended on trade, markets, and conquest for dissemination of objects over distances and for cultural transfer, appropriation, and assimilation in other geopolitical contexts. As Espagne observes in his impressive historical overview, there are many important examples of this, such as the Silk Road, the Portuguese spice route, and Constantinople as a commercial "contact zone" between Turkey and Europe, Christian and Muslim cultures.

One of the principal causes of globalization before circa I 800 is of course colonization. In his illuminating chapter on the worldwide diffusion of art and culture from Spain, Portugal, and, to a lesser extent, Italy between the late Middle Ages and the beginning of modernity, Gruzinski convincingly argues that the idea of "Western" art was born in translation, so to speak. The notions of "Western" art, philosopy, and culture were products of colonial encounters with other cultures, suggests Gruzinski: "A 'Western' art began to beat out a path for itself, starting from the workshops opened in Mexico, Lima, Quito, Gao, and Nagasaki" (p. 5I). In other words, "Western" art emerged with the distribution and adaptation of European cultural products and ways of thinking in the colonies. Gruzinski does not forget the fact that violence and "a balance of forces" (p. 52) were involved in colonial transculturation processes, and he sheds interesting new light on what was gained in these unequal cultural encounters. However, his chapter reflects a general tendency in the book to bypass the darker, destructive side of colonialism and imperialism. It has little to say about the fact that cultural traditions, monuments, arts, and artefacts can also perish as a result of transcultural "circulations" and "exchanges" such as war, conquest, and slave trade. Considering the book's emphasis on Western cultures and cultural dissemination in the centuries of colonization and imperialism, as well as its revisionist ambitions, one wonders why the editors did not include a discussion of the difficult but important question of how a global art history can address extinctions, silences, intergenerational traumas, and gaps in knowledge caused by destructive intercultural exchange, past and present. To mention just the most obvious example: How can the transcultural artistic practices and heritage resulting from the "circulation" of enslaved people from Africa 
to European colonies be mapped, for instance, by drawing on the new tools of digital humanities? How can the results of such mappings be transformed into a new ethically responsible narrative structure?

The book concludes with a perceptive afterword by art historian James Elkins, a protagonist of the critique of the ambition to write a "universal history," which underpins this book as well as many of the historical attempts to write a world art history. Elkins's thorough analysis of the problems involved in this project ensures that the critical discussion of the new positions and methods presented by the authors is opened up by the book itself. His approach is constructively critical in the sense that all his objections are put forward with the aim of developing sound and ethically valid ways of writing global art history. Elkins's afterword reveals that the contributors' confidence in the promises that "circulation" holds for future research is both the greatest strength and the greatest weakness of the book. On the one hand, several contributors suggest that an emphasis on cultural exchanges might in and of itself solve the problems of Eurocentrism, hierarchicalization, othering, and exclusion inherent to Western art historical narratives. As Sophie Cras's and Piotr Piotrowski's chapters on conceptual art demonstrate, circulation does not exclude the establishment of cultural and artistic hegemonies or the unequal distribution of power and marginalization of so-called peripheries. On the other hand, the concept of circulation opens up new possibilities and ways of studying the reciprocal relations between different locales. The discipline of art history has always been dominated by qualitative hermeneutic methods. It is a token of the innovative spirit of this book that no less than three of the chapters aim to change this by engaging with digital humanities, compiling large datasets and using digital tools for mapping in order to explore what quantitative methods could add to the existing methodologies. In several of the case studies, the use of maps has produced unexpected and eye-opening results, which deepen our understanding of exchanges between artists in different countries. As Elkins suggests, "It may be that the most promising sort of circulation in this book is the one in which the mapmaker sees that her map suggests different starting places for the next inquiry" (p. $5 \mathrm{I}$ ).

This is a commendable and highly useful book written by erudite scholars. It is not only rich in historical information, but also introduces and evaluates new tools and approaches for future studies in (art) history. It thus marks the beginning of more collaborative, transcultural, and systematically comparative approaches in the discipline of art history.

ANNE RING PETERSEN University of Copenhagen 